\title{
ANODIC OXIDATION OF POROUS ALUMINIUM PELLETS
}

\author{
W. J. BERNARD and E. J. FRESIA \\ Research and Development Center, Sprague Electric Company North Adams, Massachusetts 01247
}

(Received October 6, 1973)

\begin{abstract}
The anodization of porous aluminum pellets is accompanied by a change in the composition of the electrolyte within the pellet pores. This change can be accounted for by electrochemical transport of ions to the electrodes and the inability of the system to overcome the concentrating effects in the anolyte. It is shown that this effect can, depending on the composition of the bulk electrolyte, result in a strong acid environment or a weakly conducting electrolyte within the pellet. Either condition results in undesirable oxidizing characteristics; a strong acid will lead to the formation of a porous film which is poorly impregnated by the solid electrolyte, and the resistive electrolyte impedes the growth of oxide film. This work indicates that these extreme conditions may be avoided by the use of electrolytes containing salts of organic acids of moderate strength.
\end{abstract}

An electronic component with significant commercial potential is the aluminum counterpart of the solid electrolyte tantalum capacitor. Aluminum powder of high purity is available at very low cost relative to tantalum powder, and its density is one-sixth that of tantalum. Thus, even though the dielectric content of $\mathrm{Ta}_{2} \mathrm{O}_{5}$ is about three times as great as that of $\mathrm{Al}_{2} \mathrm{O}_{3}$, it is clear from simple calculations that, for powder of comparable surface area, the cost per farad-volt of aluminum solid electrolyte capacitors would be far less than those constructed of tantalum. In our laboratories we have constructed large numbers of such capacitors on an experimental basis. The effort has been pursued along two avenues, the development of a hermetically sealed device and a resin encapsulated device. The first approach has been partially conducted under a U.S. Army Electronics Command contract.

Early in the development of the solid aluminum capacitor, it was observed that the dry capacitance obtained was only 70 to $75 \%$ of the wet capacitance, i.e., the capacitance recovery did not approach the 95 to $100 \%$ value that the solid tantalum capacitor will yield. The so-called lost capacitance could be recovered by immersing the manganese dioxide coated pellet in a liquid electrolyte or by exposing the capacitor to high humidity. Thus, it was realized that the $\mathrm{MnO}_{2}$ was not contacting all of the available surface area, and this available surface area results in a potentially unstable capacitor when subjected to high humidity conditions in a nonhermetically sealed package. Prototype resin encapsulated units did in fact exhibit such instability, and capacitance increases of 25 to $30 \%$ were observed when the capacitors were exposed to humidity tests.
These capacitance effects have been attributed to the structure of the oxide film, which in the pellet interior is believed to consist of a barrier layer and a superimposed thick porous layer. Examination of the oxide film thickness within anodized porous pellets revealed non-uniform interference colors, indicative of a large variation in the oxide thickness throughout the pellet. Although quite reproducible color patterns were found for each pellet size, the patterns or color distribution varied with the pellet diameter. Study of the interference colors from the outer edge of pellet into the center indicated that the oxide became considerably thicker towards the middle of the pellet.

The reason for the nonuniform oxide thickness lies in the nature of the porous pellet. Within its pores, the ratio of metal surface area to electrolyte volume is many times greater than under the conditions in which foil is anodized. In the conventional case, the electrochemical reactions at the anode bring about only a negligible change in electrolyte composition, and any localized concentration differences which develop are quickly adjusted by stirring and natural convection. This compensation does not occur with a porous pellet. The very small volume of electrolyte within a pore may undergo profound compositional changes in the process of supplying oxygen to the metal, and access of fresh solution from the bulk electrolyte to the pores cannot be achieved by stirring (except for a short distance into the structure). Thus, the electrochemically-created concentration effects can only be reduced by diffusion and convection, and in the unfavorable pellet geometry characterized by highly constricted channels, these processes have no appreciable effect. Therefore, in the case of dilute acids and for some salt solutions, as described below, 
the electrolyte in the pellet interior becomes more acidic as anodization proceeds.

This phenomenon was observed in studies performed earlier on sintered tantalum pellets. In the tantalum work, it was found that during anodizations in $0.001 \mathrm{M}$ phosphoric acid, the acid becomes highly concentrated within the pores of the pellet; concentrations of acid higher than $1.0 \mathrm{M}$ within the pellet pores were determined. This internal concentration varied with the current density used during anodization.

It is quite obvious that the same concentration effect will occur within the pores of an aluminum pellet, and it is well-known that phosphate solutions of low $\mathrm{pH}$ promote the growth of thick porous films on aluminum. The concentration gradient within a pellet would be such that the acidity would increase as the center of the pellet was approached. Thus, the oxide should be thicker toward the middle of the pellet and this is precisely what the interference colors indicate. Imperfect filling of the oxide pores of the thicker film by $\mathrm{MnO}_{2}$ would lead to the observed loss of capacitance in the finished capacitor and provide an unstable condition when exposed to a high humidity environment.

\section{EXPERIMENTAL DETAILS}

Pellets were pressed from aluminum powder of 99.99\% purity (exclusive of oxide). The pore size distribution, as determined by the mercury intrusion method, gave a range of $0.7 \mu$ to $10 \mu$ with the average occurring at $5.1 \mu$.

Anodizations were carried out in a thermostated cell maintained at a constant temperature of $90^{\circ} \mathrm{C}$, with the solutions stirred vigorously during the entire experiment. The cathode was a platinum cylinder $1.0 \mathrm{~cm}$ in diameter. The formation current was held constant at $11.5 \mathrm{ma}, 50 \mathrm{ma}$, and $75 \mathrm{ma}$ for the pellets with diameters of $0.31 \mathrm{~cm}, 0.48 \mathrm{~cm}$ and $0.57 \mathrm{~cm}$, respectively, until a terminal voltage of $100 \mathrm{~V}$ was achieved. This was followed by a constant voltage period of one hour. Anodes were washed in distilled water for several hours to remove electrolyte residue and then dried at $100^{\circ} \mathrm{C}$ for a few minutes.

Capacitance was measured vs. a platinized platinum cylindrical electrode at $120 \mathrm{~Hz}$ in a saturated ammonium formate solution $(\rho=4.7 \Omega$-cm at $\left.25^{\circ} \mathrm{C}\right)$.

Examination of the uniformity of the oxide film thickness within the porous pellet was made by use of a technique described by Basinska, et al. ${ }^{1}$, which involves the evaporation of a thin layer of gold over the oxide layer. This technique produces relatively bright interference colors, the color being an indication of the thickness of the oxide film. Pellets were broken along the longitudinal axis as well as perpendicular to this axis, and a thin layer of gold was evaporated on the oxide coated structure. Aluminum foils anodized to various voltages to yield different oxide thicknesses were prepared and gold was evaporated on the surface. This provided a step-gauge for estimating oxide thickness.

The increase in acid concentration within pellet pores was determined by two methods: (1) measurement of the decrease in conductance of the bulk electrolyte during anodization, and (2) measurement of the increase in conductance of a small volume of water used to leach the acid from the anodized pellet. In the latter case, the $\mathrm{pH}$ of the final solution could be used to confirm the calculated value of phosphoric acid in the leaching water. The phosphoric acid content of the anode was then calculated by knowledge of the free volume of the porous pellet.

\section{RESULTS}

When the acid which is being concentrated within the pellets is a strong acid, as is the case when anodization is carried out in phosphate solutions, the structure and composition of the oxide film may be affected. However, formation in salts of weak acids may create another kind of undesirable situation. The effect with borates is especially pronounced: If an aqueous solution of sodium borate and boric acid of pH 5.4 is used as the electrolyte, the application of a constant current brings about an anomolously rapid rise in the potential drop across the anode, giving an apparent rate of formation much greater than observed in anodization with phosphate solutions. Abnormally high capacitance values are observed, and visual examination of oxide film thickness in the pellet interior shows the presence of a very thin oxide in that region. The effect also occurs with nonaqueous borate solutions. Solutions of ammonium borates in ethylene glycol are commonly employed in the capacitor industry as fill- or working-electrolytes, and are also known to form good dielectric films on aluminum with high current efficiency ${ }^{2}$. However, when used to anodize pellets, the results can be even poorer than with aqueous borates.

Table I summarizes the data obtained with anodization to $100 \mathrm{~V}$ of three different diameter pellets and gives comparative data with smooth $\mathrm{Al}$ 
TABLE I

Formation rates and capacitances of aluminum foil and pellets.

\begin{tabular}{lccc}
\hline & $\begin{array}{l}0.01 \mathrm{M} \text { Sodium Di- } \\
\text { hydrogen Phosphate }\end{array}$ & $\begin{array}{l}0.002 \mathrm{M} \text { Borax } \\
0.65 \mathrm{M} \text { Boric Acid }\end{array}$ & $\begin{array}{l}\text { 30\% Ammonium Penta- } \\
\text { borate in Ethylene } \\
\text { Glycol }\end{array}$ \\
\hline $\mathrm{pH}\left(25^{\circ} \mathrm{C}\right)$ & 5.45 & 5.39 & 5.10 \\
Resistivity $\left(\Omega-\mathrm{cm}, 90^{\circ} \mathrm{C}\right)$ & 490 & 1260 & 115 \\
& & & \\
Foil & 24.1 & 18.8 & 23.9 \\
Formation rate $\left(\mathrm{V} / \mathrm{min}^{2}\right)$ & 0.0504 & 0.0665 & 0.0683 \\
Capacitance $\left(\mu \mathrm{F} / \mathrm{cm}^{2}\right)$ & & & 4.98 \\
Pellet $-0.31 \mathrm{~cm}$ diameter & 3.79 & 5.42 & 118 \\
Formation rate $(\mathrm{V} / \mathrm{min})$ & 82.2 & 101 & \\
Capacitance $(\mu \mathrm{F} / \mathrm{gram})$ & & 13.3 & 7.87 \\
Pellet $-0.48 \mathrm{~cm}$ diameter & 3.38 & 248 & 270 \\
Formation rate $(\mathrm{V} / \mathrm{min})$ & 87.1 & & 9.23 \\
Capacitance $(\mu \mathrm{F} / \mathrm{gram})$ & & 13.2 & 323 \\
Pellet $-0.57 \mathrm{~cm}$ diameter & 3.32 & 251 & \\
Formation rate $(\mathrm{V} / \mathrm{min})$ & 86.7 & & \\
Capacitance $(\mu \mathrm{F} / \mathrm{gram})$ & & & \\
\hline
\end{tabular}

foil. The effect of pellet diameter on formation properties is illustrated graphically in Figures 1 and 2, in which anodization rates and capacitances for the borate solutions are normalized with respect to formation in $\mathrm{NaH}_{2} \mathrm{PO}_{4}$ solution. It is apparent that

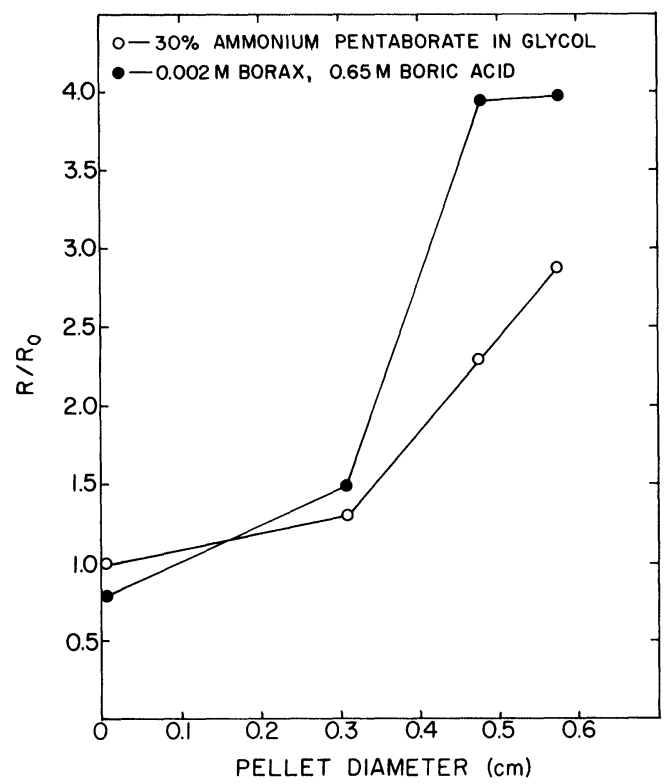

FIGURE 1 Anodization rates at $90^{\circ} \mathrm{C}$ of aluminum pellets in borate solutions, normalized with respect to the anodization rates in aqueous sodium dihydrogen phosphate, as a function of pellet diameter. the deviation from 'normal' formation behavior defined by the data for foil, and plotted at the zero-diameter line - increases with increasing pellet diameter. It is significant that formation rates and

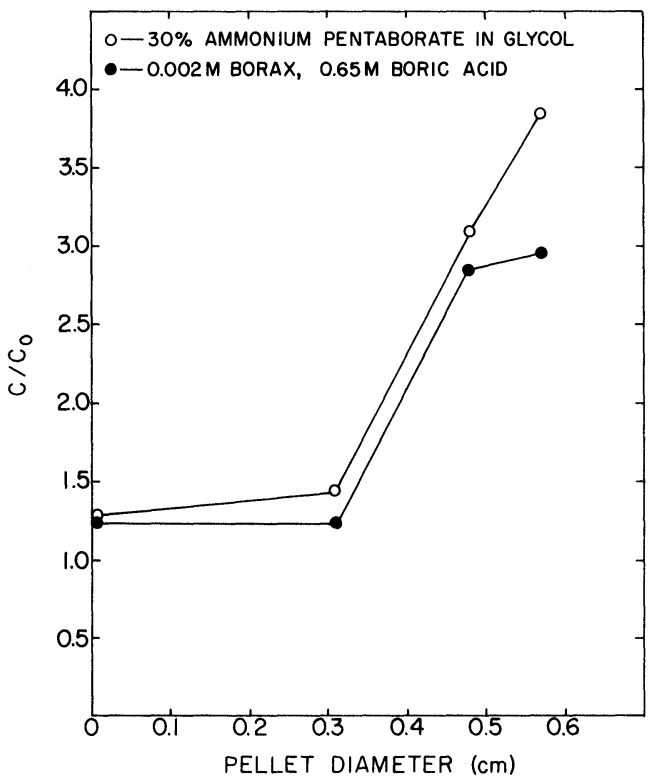

FIGURE 2 Capacitance at $120 \mathrm{~Hz}$ of aluminum pellets anodized at $90^{\circ} \mathrm{C}$ to $100 \mathrm{~V}$ in borate solutions, normalized with respect to the capacitance of pellets formed under the same conditions in aqueous sodium dihydrogen phosphate, as a function of pellet diameter. 
capacitances for foil formed in borate solutions are only slightly different from those formed in $\mathrm{NaH}_{2} \mathrm{PO}_{4}$; some difference is expected since films formed in $\mathrm{NaH}_{2} \mathrm{PO}_{4}$ differ in composition from those formed in borates ${ }^{3}$. Therefore, the very large differences in the pellet behavior cannot be ascribed to basic differences in film-forming characteristics of these dissimilar electrolytes, but must be due to pellet-electrolyte interaction. The high apparent formation rates and capacitances of pellets formed in borates are in agreement with the colors of the oxide films in the pellet interior, showing that the potential across the entire film varied widely and did not attain $100 \mathrm{~V}$ over much of the anode surface. The explanation is again to be found in the change in electrolyte composition which occurs during the passage of charge. In this case, the anolyte becomes enriched in weakly conducting boric acid and depleted in sodium ion, and accordingly develops a large increase in resistivity. The rapid rise in voltage during anodization is therefore explained by a successful anodization to the terminal voltage at the pellet exterior, but within the pellet center to a combination of a thin oxide in series with a large potential drop in the electrolyte. A prolonged hold period at constant voltage may result in some further thickening of the oxide film, since the iR loss will diminish as the current drops, but as the current decreases the rate of oxide growth may fall to too low a value to be useful.

\section{DISCUSSION}

It is apparent that the successful formation of anodic oxide throughout an aluminum sintered pellet will be dependent upon the proper selection of electrolyte, and that this selection, to some extent, will be governed by principles that are not usually considered when foil is anodized.

In the electrochemical reaction which produces aluminum oxide at the anode, the source of oxygen is water in the electrolyte, and the loss of oxygen results in the generation of hydrogen ions. The net anodic reaction can be written:

$$
3 \mathrm{H}_{2} \mathrm{O}+2 \mathrm{Al}=\mathrm{Al}_{2} \mathrm{O}_{3}+6 \mathrm{H}^{+}+6 \mathrm{e}^{-} .
$$

To maintain electroneutrality in the anolyte, one or more of the following electromigration steps must occur:

a) outward migration of $\mathrm{H}^{+}$

b) outward migration of solute cation, $\mathrm{M}^{+}$ c) inward migration of $\mathrm{OH}$

d) inward migration of solute anion, $\mathrm{A}^{-}$

All of these processes can occur, and the extent to which any particular one does is determined by its transport number, $t$, which is proportional to its ion concentration and mobility, $\mu$. In this discussion, the contribution of hydroxide ion may be neglected, since its concentration in any of the electrolytes under consideration remains too low throughout the entire process to provide any significant ion transport. Thus, the transport number of hydrogen ion is

$$
\mathrm{t}_{\mathrm{H}^{+}}=\frac{\left[\mathrm{H}^{+}\right] \mu_{\mathrm{H}^{+}}}{\left[\mathrm{H}^{+}\right] \mu_{\mathrm{H}^{+}}+\left[\mathrm{M}^{+}\right] \mu_{\mathrm{M}^{+}}+\left[\mathrm{A}^{-}\right] \mu_{\mathrm{A}^{-}}}
$$

and similarly for the other ions. The sum of the transport numbers is equal to unity.

Table II lists the ionic mobilities for a number of ions of interest. Although these values are generally the limiting values, i.e., at infinite dilutions, and for temperatures well below $90^{\circ} \mathrm{C}$, they may be taken as useful approximations for the actual experimental conditions considered here - at least, at the start of electrolysis.

TABLE II

Limiting ionic mobilities in water at $25^{\circ} \mathrm{C}$.

\begin{tabular}{lcc}
\hline Ion & Mobility & Ref. \\
\hline $\mathrm{H}_{3} \mathrm{O}^{+}$ & 349.8 & $(4)$ \\
$\mathrm{Na}^{+}$ & 50.1 & $(4)$ \\
$\mathrm{NH}_{4}^{+}$ & 73.4 & $(4)$ \\
$\mathrm{OH}^{-}$ & 198 & $(4)$ \\
$\mathrm{H}_{2} \mathrm{PO}_{4}^{-}$ & 33.0 & $(5)$ \\
$\mathrm{H}_{2} \mathrm{BO}_{3}^{-}$ & $33^{\mathrm{a}}$ & $(6)$ \\
Salicylate $^{-}$ & 34 & $(6)$ \\
Glycolate $^{-}$ & 40 & $(6)$ \\
Benzoate $^{-}$ & 33 & $(6)$ \\
Citrate $^{-}$ & 28 & $(6)$ \\
\hline
\end{tabular}

a $18^{\circ} \mathrm{C}$

It is readily seen that the mobility of hydrogen ion is so large that in solutions of low $\mathrm{pH}$ it would be expected to be the dominant current transporting ion. But, in a dilute solution of sodium dihydrogen phosphate with a $\mathrm{pH}$ of 5.45 , the initial $\mathrm{t}_{\mathrm{H}^{+}}$is negligible, and $\mathrm{t}_{\mathrm{H}_{2}} \mathrm{PO}{ }_{4}{ }^{-}=0.4$, the remainder of the current being carried by outward migration of $\mathrm{Na}^{+}$. Therefore, the phosphoric acid concentration in the anolyte increases rapidly until the concentration becomes significantly large so that outward migration 
TABLE III

Formation effectiveness of $0.02 \mathrm{M}$ solutions of organic salts in a 25-75 water-ethylene glycol solvent.

\begin{tabular}{lclll}
\hline Salt & $\begin{array}{l}\text { Electrolyte } \\
\text { Resistivity } \\
\left(\Omega \text {-cm, } 90^{\circ} \mathrm{C}\right)\end{array}$ & Acid K & $\begin{array}{l}0.1 \mathrm{M} \text { Acid } \\
\text { Resistivity } \\
\left(\Omega \text {-cm, } 90^{\circ} \mathrm{C}\right)\end{array}$ & $\begin{array}{l}\text { Formation } \\
\text { Effectivness }\end{array}$ \\
\hline $\mathrm{NH}_{4}$ Salicylate & 820 & $1.06 \times 10^{-3}$ & 3040 & Excellent \\
$\left(\mathrm{NH}_{4}\right)_{2}$ Citrate & 420 & $8.7 \times 10^{-4}$ & 3280 & Good \\
$\mathrm{NH}_{4}$ Glycolate & 820 & $1.52 \times 10^{-4}$ & 8070 & Poor \\
$\mathrm{NH}_{4}$ Benzoate & 910 & $6.3 \times 10^{-5}$ & 17,300 & Very poor \\
0.002 M Borax & 1260 & $5.8 \times 10^{-10}$ & $25,700^{\mathrm{a}}$ & Very poor \\
+0.65 M Boric Acid & & & & \\
\hline
\end{tabular}

$\mathrm{a}_{1.0 \mathrm{M} \text { Aqueous solution }}$

of $\mathrm{H}^{+}$reduces the rate of acid buildup. Even then, however, the $\mathrm{H}^{+}$may fail to transport a significant part of the current. It has been reported by Merenkov ${ }^{7}$ that the high mobility of $\mathrm{H}^{+}$disappears in strong acid solution and the anion becomes the principle current carrier. Indeed, in some solutions, the anion is the sole conductor, showing the type of unilateral transport observed with certain ions in the solid state and in fused salts. This is in agreement with our observations with the anodization of tantalum in $0.001 \mathrm{M} \mathrm{H}_{3} \mathrm{PO}_{4}$ in which the anolyte attained an acid concentration greater than $1.0 \mathrm{M} \dagger \mathrm{In}$ a well-stirred solution using smooth anodes, the effect upon the anode process may be negligible, but the consequences within the constraints of a porous pellet are significant; instead of a dilute neutral solution, the metal surface becomes anodized in a solution of phosphoric acid of low $\mathrm{pH}$ and under these circumstances a thick porous film may be developed. However, the high conductivity of aqueous phosphoric acid solutions prevents any significant potential drop to develop across the electrolyte within the pores, and thus permits the pellet interior surfaces to reach essentially the same potential as the exterior.

In the case of borates, on the other hand, production of oxide at the anode causes the electrolyte conductivity to decrease. The outward migration of salt cation and the inward migration of borate ion increases the concentration of boric acid, which is so slightly dissociated $\left(\mathrm{K}_{1}=5.8 \times 10^{-10}\right)$ that the anolyte resistivity increases. This causes a rapid rise in voltage at constant current without the attendant

$\dagger$ Although the same electrolyte changes occur when tantalum pellets are anodized, the production of a strongly acidic solution does not have the same adverse effect on the formation behavior of tantalum. increase in oxide thickness normally associated with that voltage rise.

The selection of a useful anodizing electrolyte is thus restricted by at least the following considerations:

a) Salts of strong acids are undesirable, since the pellet interior will soon be subjected to a strong acid environment,

b) Salts of very weak acids will generate highly resistant solutions within the porous pellet structure and reduce the formation rate to an impractical level.

Salts of acids with $\mathrm{K}_{\mathrm{I}}$ between $10^{-3}$ and $10^{-5}$ would probably be the best choice; there are a number of organic acids that are known to form acceptable oxide films on aluminum foil and whose dissociation constants fall within this range. Salts of several of these acids were used in experiments and evaluated on the basis of their 'Formation Effectiveness,' that is, the degree to which they permitted a uniform oxide film to be formed throughout the pellet. In these experiments a mixed solvent, consisting of $25 \%$ water and $75 \%$ ethylene glycol, was used for both the salts and the acid solutions for which conductivity data was obtained.

The results are shown in Table III, including data for aqueous boric acid for comparison. The electrolytes are qualitatively graded on the basis of the degrees of uniformity of oxide film colors through the pellet cross section.

It is clear that the order is directly related to the dissociation constant of the acid from which the electrolyte salts were prepared, and thus to the conductivity of the acid solutions within the pores, and not to the conductivity of the bulk electrolytes. The choice of $0.1 \mathrm{M}$ acid concentration in the pore structures for purposes of comparison of conductivity was arbitrary; it could well be higher. It is easy to see 
that $0.1 \mathrm{M}$ solutions are easily achieved when one considers the small volume of electrolyte contained within the pores in relation to the high current passed. The total volume of the largest pellet was $0.26 \mathrm{~cm}^{3}$ and at a porosity of $43 \%$ its volume was $0.11 \mathrm{~cm}^{3}$. To generate $0.1 \mathrm{M}$ acid in that space $\left(1.1 \times 10^{-5}\right.$ equivalents of $\left.\mathrm{H}^{+}\right)$would require only 14 seconds at the formation current of $75 \mathrm{ma}$. Even allowing for nonuniform current distribution, the charge necessary for this change in concentration would easily be obtained during the formation period which ranged from 5 to 25 minutes.

\section{ACKNOWLEDGEMENTS}

The authors wish to express their appreciation to Dr. J. J. Randall and Mr. A. Whitman for their useful comments and suggestions.

\section{REFERENCES}

1. S. J. Basinska, J. J. Polling and A. Charlesby, Acta Met., 2, 313 (1954).

2. W. J. Bernard and J. W. Cook, J. Electrochem. Soc.,106, 643 (1959).

3. R. C. Plumb, J. Electrochem Soc., 105, 498 (1958).

4. G. Kortum and J. O'M. Bockris, Textbook of Electrochemistry, (Elsevier, New York, N. Y., 1951) p. 205.

5. C. M. Mason and J. B. Culvern, J. Amer. Chem. Soc., 71, 2387 (1949).

6. International Critical Tables, (McGraw-Hill, New York, N. Y., 1929) Vol. VI.

7. P. T. Merenkov, Uzbeksk. Khim. Zh., 6, 35 (1962). 

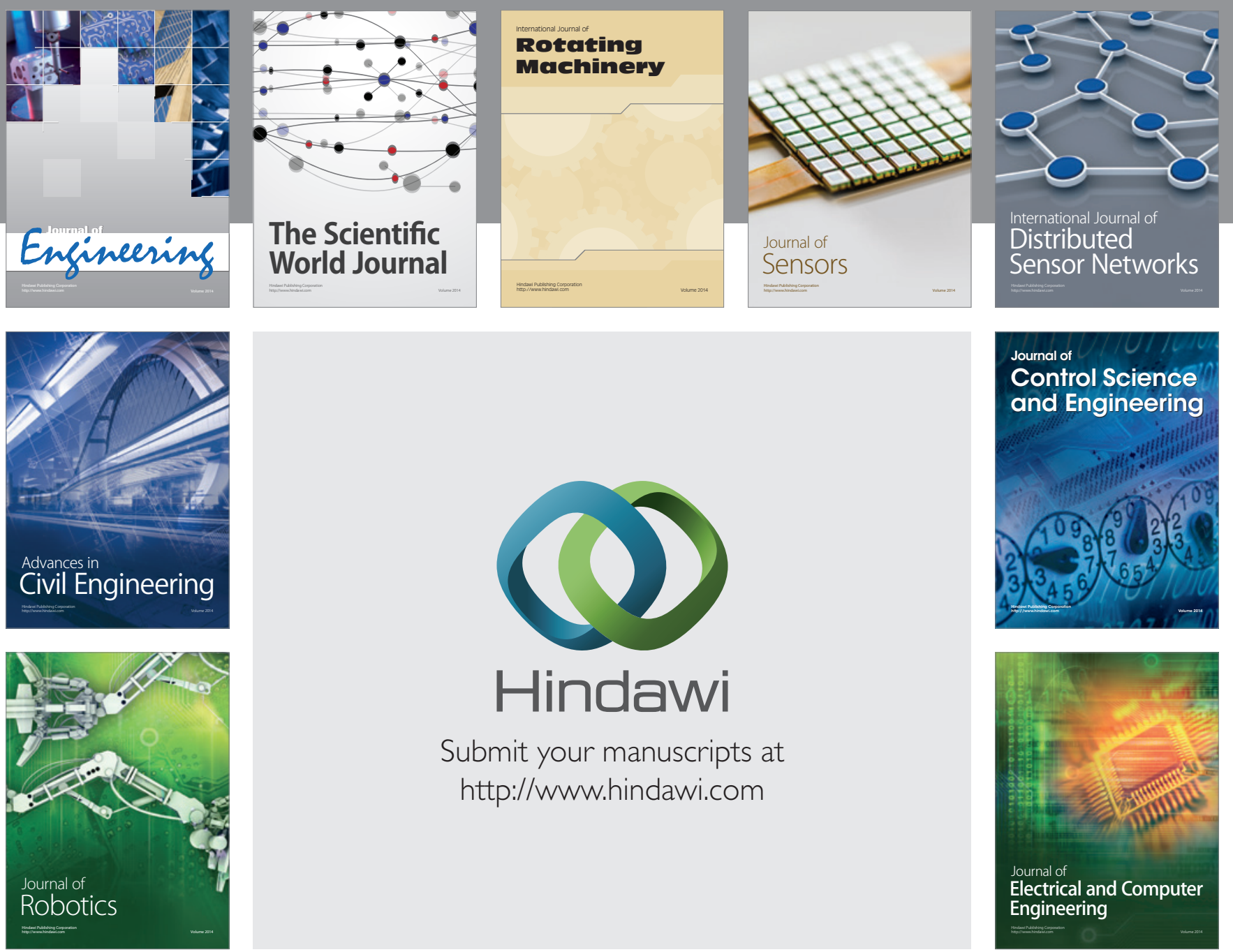

Submit your manuscripts at

http://www.hindawi.com
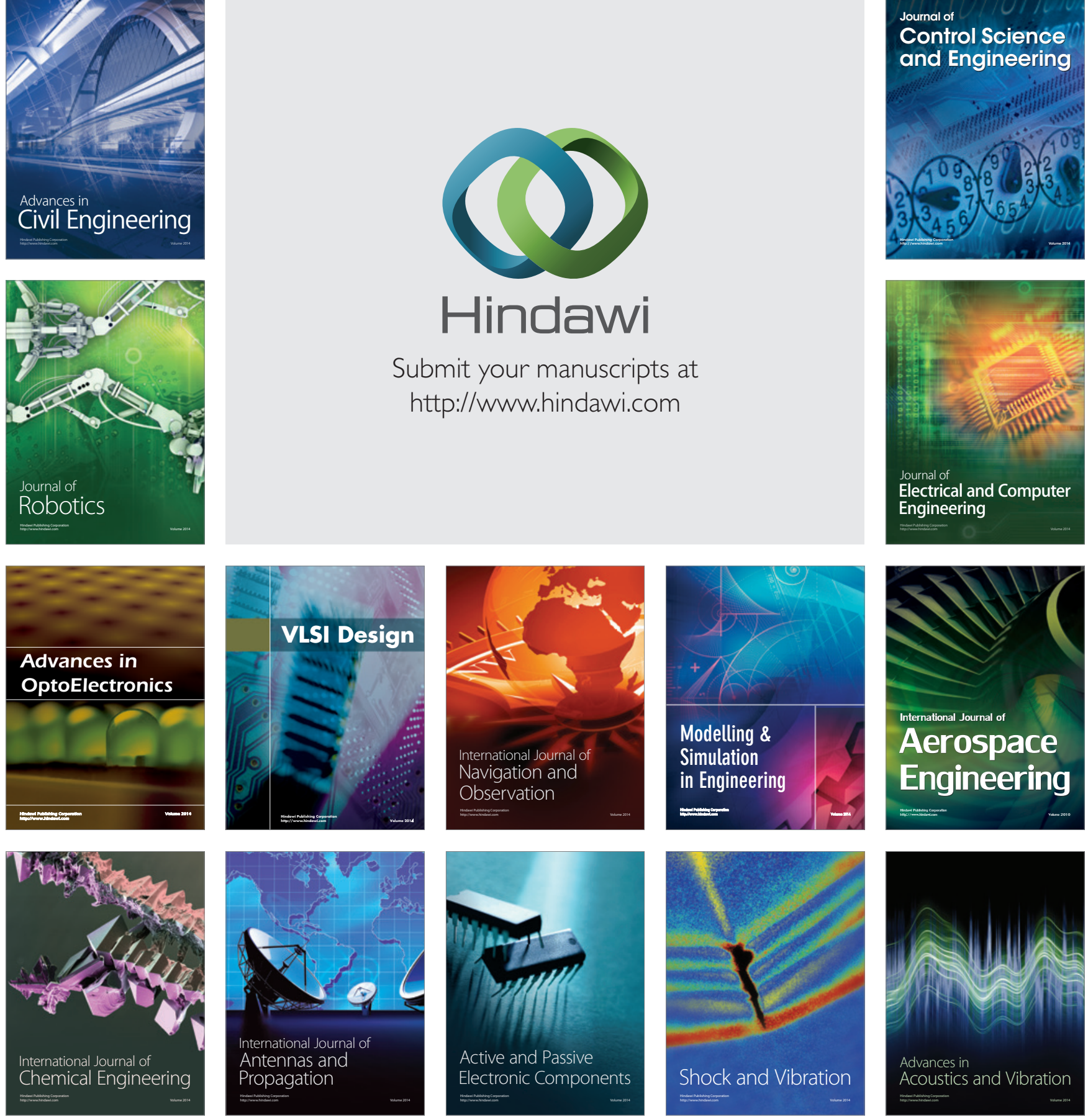